\title{
RESISTENCIA A LA COSIFICACIÓN DESDE LAS REPRESENTACIONES HEREDADAS. \\ EL CASO DEL DOCUMENTAL LA MUJER, COSA DE HOMBRES
}

\section{Rosario Torres}

rzt1@psu.edu

The Pennsylvania State University

(Berks Campus) - Estados Unidos

Recibido: 28-01-2012

Aceptado: 17-03-2012

\section{Resumen}

El presente artículo analiza el documental de Isabel Coixet La mujer, cosa de hombres (2009), el cual refleja la publicidad emitida en televisiones españolas en los últimos 50 años y su impacto en la audiencia. Se examina a continuación cómo la directora: invita a plantearse la conexión entre la distribución de roles tradicionales (diseminados por spots publicitarios) y el abuso doméstico; explora el tratamiento de este asunto en la televisión y, finalmente, dota de visibilidad a un tema tradicionalmente tabú, invitando al diálogo y a la reflexión y sugiriendo el replanteamiento de presupuestos sociales profundamente enraizados.

Palabras Clave: Publicidad, estereotipos, televisión, telediario, violencia doméstica, Coixet.

\begin{abstract}
This article analyzes Isabel Coixet's documentary La mujer, cosa de hombres (2009), which reflects the advertising broadcast in Spanish televisions in the last 50 years and its impact in the audience. It is then examined how the director invites to think about the connection between the distribution of traditional roles (conveyed by advertisements) and domestic abuse; explores the treatment of this matter on television, and finally gives visibility to a traditionally taboo theme, encouraging dialogue and reflection and proposing the reconsideration of deeply rooted social assumptions.
\end{abstract}

Keywords: Advertising, stereotypes, television, television news, domestic violence, Coixet. 


\section{Introducción}

Aunque la función primaria de la publicidad es la divulgación de mensajes de carácter comercial para atraer a posibles compradores, su objetivo secundario consiste en la creación de estructuras de significado que moldeen y reflejen la vida contemporánea. Los anuncios distribuidos desde distintos medios de comunicación van conformando una superestructura, aparentemente autónoma, de notable influencia.

Las campañas actuales trascienden las técnicas características de las primigenias, consistentes en la simple certificación de la existencia de una mercancía a vender o en convencer de cuán útil era para la audiencia; hoy día los consumidores están expuestos a las técnicas contextualizadoras típicas de la actual fase de la publicidad, caracterizada por situar el producto en universos muy específicos e iniciada en los años sesenta.

Fue entonces cuando España experimentó un boom publicitario, en el entorno del crecimiento económico del país, la expansión turística, la llegada de agencias multinacionales y la creación de la primera escuela de publicidad y relaciones públicas. La producción en masa de electrodomésticos y aparatos para el hogar incrementó y con ella el volumen de anuncios destinados a promocionarlos; gran parte de tales campañas se crearon para influenciar a la mujer, que solía (y suele aún) adquirir la mayoría de los productos del ámbito doméstico.

\section{Metodología utilizada}

El método de investigación del presente artículo parte del análisis de la segmentación del documental estudiado. Esta división del texto en unidades significativas facilita la comprensión de su articulación interna según ciertas reglas discursivas y el orden que presentan, de manera que el espacio textual audiovisual de La mujer, cosa de hombres va quedando definido. Este análisis formal inicial provee de la base heurística necesaria en la que profundizar a través de un acercamiento semiótico.

Tal estudio semiológico se extiende a la esfera de los estudios culturales, para devenir en un análisis ideológico que explora tanto el proceso de creación de estructuras simbólicas por parte de la publicidad como aquellos de sus mensajes que históricamente han animado a la audiencia femenina a reproducir roles de género tradicionales. Esta práctica metodológica pone de manifiesto la circulación de significados entre la publicidad, la ideología y la audiencia televisiva, para así acceder a la complejidad de su discurso.

Como Barthes explica en Mithologies, conviene desmontar semióticamente el lenguaje de la cultura de masas, ya que si se consideran "las representaciones colectivas como sistema de signos, podríamos alentar la esperanza de salir de la denuncia piadosa y dar cuenta en detalle de la mistificación que transforma la cultura pequeño-burguesa en naturaleza universal" (Barthes, 1972: 7). 


\section{Análisis del documental La mujer, cosa de hombres}

La serie documental 50 años de... (proyecto de TVE sobre diferentes aspectos de la sociedad y su evolución durante las últimas cinco décadas) refleja en su capítulo La mujer, cosa de hombres la publicidad emitida en televisiones españolas, desde aproximadamente 1960 a 2009, así como su impacto en la audiencia femenina. Isabel Coixet dirigió este ambicioso proyecto en 2009, con el objetivo de describir el "tradicional papel de la mujer en la sociedad española y la repercusión que tienen en los medios los delitos por violencia de género" (RTVE, 2009).

La directora tiene como punto de partida el reconocimiento del poder de creación de estructuras simbólicas por parte de la publicidad y explora específicamente aquellos mensajes que han animado a la audiencia a reproducir roles de género tradicionales; la mayoría de los anuncios presentados muestran mujeres realizando labores del hogar, limpiando, cocinando, ocupándose de su aspecto físico y cuidando de su esposo e hijos, permaneciendo siempre en el ámbito privado de la casa. El documental invita a plantearse la posible conexión entre este modelo de distribución de roles y el abuso doméstico y también explora el tratamiento que este asunto recibe en los programas producidos precisamente por el mismo medio de comunicación que emite dichos anuncios, la televisión.

La estructura del capítulo consiste en la concatenación de un total de 121 documentos audiovisuales distintos, procedentes de material de Radio Televisión Española. La edición del producto resultante se basa en la división de tales contenidos en dos categorías: por un lado, se encuentran anuncios emitidos en televisión, actuaciones musicales, imágenes de archivo y canciones de fondo y, por otro, noticias, sobre sucesos mortales de violencia doméstica, extraídas de telediarios.

La mujer, cosa de hombres nace de la meticulosa alternación de documentos de cada tipo, durante aproximadamente media hora, de forma que los sucesos de violencia quedan contextualizados en la ideología de la sociedad que los experimenta. El capítulo se inicia, por ejemplo, con un spot de coñac Soberano de los años 70, protagonizado por un ama de casa que va a consultar a una pitonisa, a la cual explica:

\footnotetext{
"Necesito su ayuda. Tengo que consultarle un terrible problema. Se trata de mi marido. Cada vez tiene peor carácter y nuestra casa está empezando a ser un verdadero infierno. Está siempre irritado y se pasa días enteros sin dirigirme la palabra. Tiene accesos de terrible cólera. Cuando me dice algo, es siempre a gritos y con malos modales. Nunca me besa cuando sale de casa".
}

Simultáneamente se muestran imágenes que describen todo ello y que incluyen al esposo tirando un plato al suelo y dando una bofetada a su compañera. La pitonisa responde entonces: 
“¿Has pensado que tu marido trabaja muchas horas diarias y que tiene derecho, cuando llega a su hogar, a encontrar un agradable recibimiento? Mira esto y comprueba que nunca le falte su copita de coñac. Verás como no falla".

Inmediatamente después, Coixet añade un fragmento del Telediario 1 de RTVE en el que la periodista informa de que "Una mujer de 35 años, Rosa Olmedo, fue asesinada por su ex-marido de varias puñaladas".

Desde el principio, la directora aborda el tema sin reparar en digresiones, con dolorosa concisión y también con originalidad; en lugar de elaborar un documental al uso, prescinde de narrador y de la estructura narrativa tradicional, sugiriendo ya, desde la forma de su capítulo, que se trata de un contenido (la violencia doméstica) que hay que contar de forma alternativa a la convencional patriarcal. La mujer, cosa de hombres no tiene voz superpuesta alguna, sino que prescinde de esta importante figura de la fílmica tradicional y de la ostensible muestra de la marca de la enunciación que conlleva.

Coixet renuncia a retener la posición supra-diegética convencional y a tratar a su audiencia con innecesaria condescendencia; la característica dirección de auteur de sus películas emerge así también en su labor documental, cuando deja que los segmentos de los telediarios y los anuncios sean los que "hablen" por sí mismos y den visibilidad a las víctimas (silenciadas brutalmente) a las que se aluden.

El discurso audiovisual convencional también ha solido consistir en la articulación de una historia en función de una narración, formato predilecto del occidente europeo desde el Renacimiento. Esta necesidad de argumento se debe a que presenta una forma de explicar el caos que es el mundo y ofrece un sentido completo que sólo es accesible desde el final del relato. La narrativa se ha basado en un continuo empujar al receptor hacia delante, manipulando su deseo por acceder, finalmente, al conocimiento. Por el contrario, Coixet segmenta su trabajo en 121 mini-narrativas, independientes, que constan de sentido por sí solas, pero que acaban trascendiéndolo una vez puestas en relación unas con otras, desde el inicio del capítulo.

Cabe destacar también que la directora no muestra las imágenes que suelen acompañar las noticias narradas por los presentadores, sino que sólo enseña el instante en que el periodista lee el encabezamiento desde el plató. No se incluye ninguna imagen de los escenarios de los asesinatos aludidos ni de sus víctimas, dejando que las representaciones que tomen protagonismo sean las de los anuncios y las de sus idealizadas proyecciones de la realidad. Se opta por el decoro y por el respeto por cada asesinada, de forma que, como explica López Quiñones, la "imposibilidad de observar lo que la voz en over relata instaura [...] una ética de la mirada porque impone en los espectadores un modelo de comprensión y empatía pos-ocular" (López-Quiñones, 2010: 247) ${ }^{1}$.

\footnotetext{
${ }^{1}$ Antonio Gómez López-Quiñones sobre el documental de Coixet: Cartas a Nora.
} 
La notable selección de anuncios emitidos por televisión, actuaciones musicales en plató, imágenes televisivas de archivo y canciones compilada en La mujer, cosa de hombres ilustra la idea de feminidad que estas formas de comunicación han ido reflejando a lo largo de 50 años, así como su repercusión en la sociedad. La televisión (y, en general, los medios de comunicación de masas) se encuentra entre los sectores que han experimentado mayor desarrollo cualitativo y cuantitativo desde los años 60 . No obstante, se ha dado la tendencia a la concentración mediática y un número relativamente reducido de corporaciones gigantes suelen acumular los medios más influyentes en televisión, prensa, radio e industria cinematográfica. Por otro lado, en la última década se ha preferido favorecer el género de entretenimiento sobre el informativo o el interpretativo/de opinión; las decisiones periodísticas y las de negocios parecen fusionarse cada vez más, no sólo por el mayor peso que se está concediendo al entretenimiento, sino porque la publicidad también está condicionando en mayor medida los contenidos mediáticos.

Por todo ello, y por la acentuada trivialización que va invadiendo el panorama mediático, el cometido supuestamente democratizador de los medios está siendo puesto en entredicho por numerosos críticos en esta actual era de la globalización. La última (IV) Conferencia Mundial de Naciones Unidas sobre las Mujeres ha dedicado gran parte de su capítulo 4 a analizar esta situación, tras observar que "los medios impresos y electrónicos de la mayoría de los países no ofrecen una imagen equilibrada de los diversos estilos de vida de las mujeres y de su aportación a la sociedad en un mundo en evolución" (Naciones Unidas, 1995: 108). El informe elaborado como resultado de sus asambleas refleja dicha preocupación y aconseja sobre cómo aprovechar el desarrollo tecnológico para enriquecer el universo mediático (en lugar de simplificarlo) y para fomentar la igualdad entre los sexos. Se proponen además concretamente:

"Medidas que han de adoptar los medios de información de masas y las organizaciones de
publicidad: a) Elaborar, en la medida en que ello no atente contra la libertad de expresión,
directrices profesionales y códigos de conducta y otras formas de autorregulación para
fomentar la presentación de imágenes no estereotipadas de la mujer; b) Establecer, en la
medida en que ello no atente contra la libertad de expresión, directrices profesionales y códigos
de conducta respecto de los materiales de contenido violento, degradante o pornográfico sobre
la mujer en los medios de información, incluso en la publicidad" (Naciones Unidas, 1995: 111).

Gran parte de los documentos audiovisuales presentados en La mujer, cosa de hombres son anuncios; los 42 spots seleccionados evidencian lo procedentes de las medidas sugeridas por Naciones Unidas y atestiguan lo desbordante que resulta la imagen de la mujer en las diversas manifestaciones icónicas de la cultura de masas, especialmente en la publicidad. Este documental concatena hábilmente los anuncios con imágenes de archivo y noticias, sugiriendo la influencia de los primeros sobre los segundos, y evidenciando también el conocimiento de cuestiones publicitarias por parte de la directora. 
Después de licenciarse en historia, Coixet se dedicó a la publicidad y a la redacción de spots y, tras ganar varios premios, fundó su propia productora en el año 2000. Desde entonces, ha realizado, no sólo cine, sino también anuncios, documentales y proyectos televisivos (como La mujer, cosa de hombres). La directora está al tanto de que la publicidad informa de la mentalidad predominante en la sociedad y de que es necesario determinar qué comunica en el fondo, como explica Bermejo:

\footnotetext{
"La publicidad no sólo da a conocer sus productos y señala sus cualidades, sino que, [...], por debajo de cada anuncio, hay muchas relaciones pensadas explícitamente para asociar el producto a valores que pueden o no estar en alza. Por otro lado, la publicidad no sólo asocia a los productos nuevos valores comúnmente aceptados, sino que también fabrica nuevos valores y modelos de vida y se los presenta a los consumidores" (Bermejo, Carballido, Patricio y Ramos, 1994: 25).
}

Por ejemplo, la mayoría de los spots mostrados en el documental están protagonizados por mujeres que limpian, utilizan electrodomésticos, cocinan o cuidan su apariencia física, actividades todas ellas que reflejan una idea de feminidad convencional y centrada en el ámbito doméstico. Estas campañas publicitarias no sólo informan de la posible utilidad de sus productos, sino también de una ideología específica y de sus expectativas: por ejemplo, el eslogan del anuncio del turrón El Panal de Jijona anima a la esposa a que, sirviéndolo, "Conquiste a los nuevos califas"; el spot del aceite Carbonell invita a la mujer a cocinar con el mismo aceite que "usaba mi madre" (como añade su esposo) y la voz superpuesta al anuncio del lavaplatos de AEG indica que este electrodoméstico existe "Para ayudar a las mujeres", a las que no "privan de ningún antojo".

Estas campañas de los años 60, 70 y 80 invitan a la audiencia no sólo a disfrutar de las propiedades de tales alimentos o electrodomésticos, sino también a concebir a una mujer que ceda la potestad a su esposo ("califa"), que se dedique a la cocina, a la manera de la generación anterior ("mi madre") y que se ocupe de la higiene de la casa, para la cual no se la priva de nada ("ningún antojo")... Se trata de discursos tradicionales, que, por otro lado, garantizan a la agencia publicitaria emisora que su mensaje se decodificará correctamente; para convertir a la audiencia en consumidora, los publicistas suelen averiguar primero cuáles son sus anhelos y después los recrean seductivamente; pero para que el receptor se deje convencer por el mensaje emitido, primero ha de ser capaz de decodificarlo, de ahí que los anuncios partan de valores conocidos por todos.

Con el objetivo de garantizar una comunicación exitosa, se repiten representaciones de la realidad social y estructuras simbólicas ya consolidadas y existentes; aunque las agencias publicitarias evalúan constantemente cuán tradicional o avanzado podrá ser su próximo producto comunicativo, suelen dejar que el discurso final se base en el status quo.

La mujer, cosa de hombres se va desarrollando durante media hora, estructurado sobre la rápida concatenación de publicidad (promocionando estilos de vida) y de noticias 
(informando de muertes causadas por la violencia machista), a un ritmo atosigante in crescendo hasta desembocar en el último fotograma, consistente en el siguiente párrafo:

\begin{abstract}
"Dedicado a todas ellas. In memoriam Ana Orantes. Sólo existen estadísticas de mujeres asesinadas desde 1999. A partir del asesinato de Ana Orantes (1997), que había acudido a televisión, una semana antes de morir quemada a manos de su marido, la violencia contra las mujeres adquiere la visibilidad que tiene estos días. Hoy en día la legislación española con la Ley integral contra la violencia es una de las más adelantadas el mundo. Pero los asesinatos son la punta del iceberg del maltrato hacia las mujeres..."
\end{abstract}

Sólo al final del documental la directora utiliza la enunciación escrita, directa, para subrayar dos cuestiones latentes en las imágenes previamente presentadas: por un lado, que en el pasado la sociedad española no se refería abiertamente al tema de la violencia de género (ni a sus orígenes, ni tampoco la cuestionaba) y, por otro, que existe. Coixet apostilla que este tipo de crimen ocurre porque la sociedad esconde ciertas nociones y expectativas, profundamente arraigadas, que dotan de valía distinta a hombres y mujeres y que pueden degenerar en violencia de género, entendida como "agresión sufrida por la mujer como consecuencia de las condiciones socioculturales que actúan sobre el género masculino y femenino, situándola en una posición de subordinación al hombre" (Menéndez Menéndez, 2000: 2).

Estos juicios de valor se manifiestan no sólo en actos de flagrante violencia, sino también de maneras menos letales y obvias. Característica fundamental de la ideología ${ }^{2}$ es que se repite constantemente y acaba consistiendo en lo obvio, por lo que el sujeto deja de cuestionarse conscientemente su experiencia del mundo (al modo del espectador que consume asiduamente televisión sin planteársela críticamente). Así lo explica la propia directora en su página web:

"Revisé la historia del cine y encontré ejemplos alucinantes de cómo la violencia doméstica ha ido prendiendo en el imaginario del espectador de manera que ésta se ha banalizado y descifrar sus códigos no nos resulta tan fácil. En casi todas las películas de Elvis Presley, hay un momento en que éste se pone a una chica en las rodillas y le da una azotaina. Después de haber visto los resultados de las "azotainas" en mujeres de verdad, esa escena ya no puede ser ni siquiera irónica. Las películas españolas de los 60 y 70 están plagadas de situaciones en las que la bofetada, el empujón, la paliza, el insulto son consideradas completamente normales, graciosas" (Coixet, 2003).

Coixet decide alternar persistentemente casos de violencia doméstica con anuncios de televisión, actuaciones musicales y canciones de fondo, reciclando así la característica retórica

\footnotetext{
${ }^{2}$ Se entiende por ideología "the sum of the ways in which people both live and represent to themselves their relationship to the conditions of their existence [...] inscribed in signifying practices- in discourses, myths, presentations and representations of the way "things are", como define Catherine Belsey (1980: 42).
} 
de la ideología (la insistencia) para volverla en contra de la misma mentalidad predominante, la cual queda al descubierto; dolorosas realidades y ficciones mediáticas quedan contextualizadas, facilitando un mayor entendimiento de ambas, denunciando la ideología soterrada y concientizando a la audiencia.

Como queda apuntado, cada anuncio está precedido y seguido de un video de un presentador de noticias que describe un crimen fatal de violencia machista (del total de 50 a los que alude el documental). Este tipo de edición sugiere que, del mismo modo que los medios pueden influir en una dirección, también pueden incitar a otra, alternativa, como, por ejemplo, es el caso de los telediarios actuales y su labor tanto informativa como concienciadora. Como explica Berganza Conde:

"[...] en la actualidad asistimos a una mayor selección por parte de informaciones que cubren
el tema de la violencia contra las mujeres fruto de un compromiso consciente de algunos
medios y periodistas por denunciar el problema. Este tipo de informaciones ofrecen, además,
con una mayor frecuencia que en épocas anteriores, una contextualización del tema y de las
circunstancias que rodean a las víctimas, en vez de ser presentadas como episodios casuales de
violencia. Ello ha ido en detrimento de la descripción de las acciones violentas como eje
principal de la información, un tipo de cobertura característico de las informaciones de sucesos,
que con frecuencia se acercan al sensacionalismo, y que poco a poco se va abandonando"
(Berganza Conde, 2003:11).

En la España de la última década se ha dedicado mayor esfuerzo investigador y concientizador al trágico tema de la violencia doméstica y también se ha producido una mayor sensibilización de los medios de comunicación respecto a cómo tratarla (como ejemplifican recientes códigos y protocolos de autorregulación creados al respecto por colectivos de periodistas).

La mujer, cosa de hombres se estrenó tan sólo cinco años después de la entrada en vigor de la novedosa Ley Integral contra la Violencia de Género, calificada en el corolario del documental por la propia Coixet como "una de las (legislaciones) más adelantadas del mundo". Esta norma recoge medidas preventivas, de información, atención, derechos laborales y protección respecto a las mujeres víctimas de la violencia de género y nace del convencimiento de que:

“[...] la violencia de género no es un problema que afecte al ámbito privado. Al contrario, se manifiesta como el símbolo más brutal de la desigualdad existente en nuestra sociedad. Se trata de una violencia que se dirige sobre las mujeres por el hecho mismo de serlo, por ser consideradas, por sus agresores, carentes de los derechos mínimos de libertad, respeto y capacidad de decisión".

Existe "hoy una mayor conciencia que en épocas anteriores sobre ésta, gracias en buena medida, al esfuerzo realizado por las organizaciones de mujeres en su lucha contra todas las 
formas de violencia de género. Ya no es un «delito invisible», sino que produce un rechazo colectivo y una evidente alarma social" (BOCG, 2004: 41).

Ya varios años antes de la finalización de La mujer, cosa de hombres, la directora había acariciado la idea de hacer un documental sobre la violencia doméstica, como explica en su página web, desde donde recuerda que una víctima:

“[...] un día, por teléfono me preguntó si el documental éste iba a servir para algo y yo no supe qué contestarle. Porque esa había sido mi intención desde el primer momento. Yo no quería hacer un documental porque me apasionara el tema. Yo quería cambiar el mundo, cambiar la percepción que se tiene de las mujeres maltratadas, a las que siempre se presenta como pequeños seres asustados, débiles cuando la realidad es que son las personas más valerosas que he conocido, taparle la boca al desgraciado de turno que dice "ellas se lo habrán buscado", "algo habrán hecho", mostrar a las mujeres que se creen a salvo de "algo así" que la solidaridad entre mujeres es de las pocas cosas a las que podemos aferrarnos" (Coixet, 2003).

\section{Resistencia a la cosificación desde la contextualización de las representaciones heredadas y su replanteamiento}

Con este capítulo de 50 años de... Coixet alcanza tal objetivo y dota de visibilidad a un tema tradicionalmente tabú, a la vez que invita al diálogo, al debate y a la reflexión. La directora defiende que la mujer deje de ser cosa de hombres, tanto en su sentido figurado (objeto) como en su acepción más ideológica (asunto).

Coixet articula este contenido a través de una forma también anti-convencional, ignorando prácticas narrativas tradicionales y sustituyéndolas por la concatenación de múltiples mini-narrativas que acaban trascendiendo su significado independiente una vez se ponen en relación unas con otras.

El ritmo de alternación de tales materiales audiovisuales va in crescendo hasta intensificarse frenéticamente al final del documental, cuando, en tan sólo medio minuto, se suceden 38 informaciones distintas sobre cómo murieron sendas víctimas ("de una cuchillada", "la descuartizó", "a puñetazos", "la arrojara al vacío rociada con gasolina"...) y sobre quiénes las asesinaron ("su esposo", "su cónyuge", "el que fue su marido", "su pareja”...) La directora desea recordarnos el final particularmente cruento y trágico de las asesinadas, muertas de las manos de aquellos se suponía debían haber querido lo mejor para ellas.

Coixet termina el documental, por lo tanto, de forma tan abrupta, directa e intuitiva como lo inició, utilizando la agobiante sucesión de dichos clips informativos para subrayar la urgencia de este serio tema y recordar que su erradicación pasa por el replanteamiento, desde el nivel de unidad familiar, de presupuestos sociales profundamente enraizados. 


\section{Bibliografía}

- Barthes, Roland (1992) [1972]: Mythologies. New York: Noonday Press.

- Berganza Conde, $\mathrm{M}^{\mathrm{a}}$ Rosa (2003): "La construcción mediática de la violencia contra las mujeres desde la Teoría del Enfoque”. En Comunicación y Sociedad, Vol. XVI, no 2, pp. 9-32.

- Bermejo, Anunciación; Carballido, Paula; Patricio, Francisco y Ramos, Mónica (1994): El imaginario social y simbólico de la mujer en los medios de comunicación de masas: el caso concreto de la publicidad. Madrid: Comunidad de Madrid, Consejería de Economía, Dirección General de Comercio y Consumo, Subdirección General de Protección al Consumidor.

- Belsey, Catherine (1980): Critical Practice. London. New York: Methuen.

- BOCG - Boletín Oficial de las Cortes Generales (2004): "Dictamen de la Comisión y escritos de mantenimiento de enmiendas para su defensa ante el Pleno". VIII Legislatura. Serie A: Proyectos de Ley 7 de octubre de 2004. Núm. 2-7. 121/000002. Orgánica de medidas de protección integral contra la violencia de género. También [en línea] Disponible en: http://www.senado.es/legis8/publicaciones/pdf/congreso/bocg/A_002-07.PDF [16/09/2011].

- Coixet, Isabel (2003): "Tanto miedo", Miss Wasabi [en línea] Disponible en: http://www.clubcultura.com/clubcine/clubcineastas/isabelcoixet/wassabi04.htm [16/09/2011].

- López-Quiñones, Antonio Gómez (2010): "Visibilidad variable en el documental: Los límites del ocularcentrismo en Invisibles”. En The Bulletin of Hispanic Studies, Vol. 87, nº 2, pp. 241-257.

- Naciones Unidas (1995): "Informe de la Cuarta Conferencia Mundial sobre la Mujer", Beijing, 4 a 15 de septiembre [en línea] Disponible en: http://www.un.org/womenwatch/ daw/beijing/pdf/BDPfA\%20S.pdf [07/10/2011].

- RTVE (2009): “50 años de...”. Capítulo: La mujer, cosa de hombres, [en línea] Disponible en: http://www.rtve.es/alacarta/videos/50-anos-de/50-anos-mujer-cosa-hombres/637890/ [16/09/2011].

- Menéndez Menéndez, Ma. Isabel (2000): "Tratamiento informativo de la violencia de género: crimen pasional, espacio doméstico y derechos fundamentales de las mujeres", [en línea] Disponible en: http://www.paideiaescuelalibre.org/Textos\%20publicados\% 20en $\% 20 \mathrm{web} /$ TRATAMIENTO\%20INFORMATIVO\%20DE\%20LA\%20VIOLENCIA\%2 0DE\%20G\%C9N.PDF [12/12/2011]. 